\title{
Ex vivo microbial leakage after using different final irrigation regimens with chlorhexidine
}

\author{
Esther NAVARRO-ESCOBAR ${ }^{1}$, Pilar BACA², María Paloma GONZÁLEZ-RODRíGUEZ³ ${ }^{3}$ María Teresa ARIAS-MOLIZ", \\ Matilde RUIZ ${ }^{5}$, Carmen María FERRER-LUQUE ${ }^{6}$
}

\begin{abstract}
1- PhD, Postgraduate Student, Department of Operative Dentistry, School of Dentistry. University of Granada, Campus de Cartuja, Colegio Máximo s/n, Granada, Spain

2- DDS, MD, PhD, Professor, Department of Preventive Dentistry, School of Dentistry, University of Granada, Campus de Cartuja, Colegio Máximo s/n, Granada, Spain.

3- DDS, PhD, Contracted Professor, Department of Operative Dentistry, School of Dentistry. University of Granada, Campus de Cartuja, Colegio Máximo s/n, Granada, Spain

4- DDS, PhD, Assistant Professor, Department of Microbiology, School of Dentistry. University of Granada, Campus de Cartuja, Colegio Máximo s/n, Granada, Spain.

5- DDS, PhD, Assistant Professor, Department of Pediatric Dentistry, School of Dentistry. University of Granada, Campus de Cartuja, Colegio Máximo s/n, Granada, Spain.

6- DDS, MD, PhD, Associate Professor, Department of Operative Dentistry, School of Dentistry. University of Granada, Campus de Cartuja, Colegio Máximo $\mathrm{s} / \mathrm{n}$, Granada, Spain.
\end{abstract}

Corresponding address: Maria Teresa Arias-Moliz - Department of Microbiology, School of Dentistry - Campus de Cartuja - Colegio Máximo s/n - E-18071 - Granada (Spain) - Phone: 34-958-249655 - Fax: 34-958-240908 - e-mail address: mtarias@ugr.es

Received: April 24, 2012 - Modification: January 4, 2013 - Accepted: January 30, 2013

\section{ABSTRACT}

\begin{abstract}
bjective: To assess the influence of final irrigation protocols with chlorhexidine in the coronal leakage of Enterococcus faecalis in filled root canals. Material and Methods: Seventy single-root canals from extracted teeth were prepared using ProTaper instruments. The irrigation protocol accomplished an alternating irrigation with $5 \mathrm{~mL}$ of $2.5 \%$ sodium hypochlorite $(\mathrm{NaOCl})$ and $17 \%$ EDTA between each file. The teeth were randomly divided into four experimental groups $(n=15)$ according to the final irrigation regimen: group 1 , without final irrigation; group 2, irrigation with $10 \mathrm{~mL} 2.0 \%$ chlorhexidine (CHX); group 3 , with a final application of $\mathrm{EC} 40^{\mathrm{TM}}$; and group 4, irrigation with the combination $(1: 1)$ of $0.2 \% \mathrm{CHX}+0.1 \%$ cetrimide (CTR). All the teeth were mounted in a two-chamber apparatus and the coronal access was exposed to E. faecalis. The presence of turbidity in the BHI broth over a period of 180 days was observed. The Friedman test was used for statistical analysis. Results: $\mathrm{EC}{ }^{\mathrm{TM}}$ varnish showed the least leakage at 180 days, and was statistically similar to $2 \% \mathrm{CHX}$. No significant differences were observed between the group without final irrigation and the $2 \% \mathrm{CHX}$ group or $0.2 \% \mathrm{CHX}+0.1 \% \mathrm{CTR}$. Conclusions: In this ex vivo study, EC40 ${ }^{\mathrm{TM}}$ showed the longest delayed coronal leakage of E. faecalis, although without significant differences from $2 \% \mathrm{CHX}$.
\end{abstract}

Key words: Bacterial leakage. Cetrimide. Chlorhexidine. Enterococcus faecalis. Irrigation.

\section{INTRODUCTION}

The use of irrigating solutions in root canal treatments is essential to dissolve organic tissue, to eliminate bacteria and to remove the smear layer formed on root canal surfaces by the action of endodontic instruments ${ }^{40}$. The alternating use of sodium hypochlorite $(\mathrm{NaOCl})$ with chelating agents, like ethylenediaminetetraacetic acid (EDTA) or citric acid, has been recommended during root canal preparation to this end ${ }^{25}$. Chlorhexidine ( $\mathrm{CHX}$ ) has also been recommended as a root canal irrigant because of its antimicrobial activity, its capacity to adhere to dental hard tissues, its gradual release (substantivity), and its low grade of toxicity 22 . Kishen, et al. ${ }^{21}$ (2008) showed that the bacterial adherence to dentin was significantly influenced by the last irrigant used on the root canal dentin; thus, $2 \% \mathrm{CHX}$ used as the final solution, alone or after $17 \%$ EDTA $-5.25 \% \mathrm{NaOCl}$, reduced the adherence of Enterococcus faecalis.

Vivacqua-Gomes, et al. ${ }^{35}$ (2002) reported a decrease in coronal leakage in root canals irrigated with a combination of $1 \% \mathrm{NaOCl}$ and $17 \%$ EDTA, or 
with $2 \% \mathrm{CHX}$ gel, than for those irrigated with only $1 \% \mathrm{NaOCl}$ or with $1 \% \mathrm{NaOCl}$ followed by $2 \% \mathrm{CHX}$ gel. When applied in the gel form, a concentration of $2 \% \mathrm{CHX}$ may exert antimicrobial activity ${ }^{15,29}$ and delay recontamination of the root canals ${ }^{6,18}$. CHX varnishes have mainly been used for the control of dental caries. The EC40 ${ }^{\mathrm{TM}}$ varnish has $35 \%$ $\mathrm{CHX}, 27 \%$ sandarac resin and $38 \%$ ethanol and is able to effectively reduce plaque acidogenicity ${ }^{17}$. $\mathrm{EC} \mathrm{O}^{\mathrm{Tm}}$ can penetrate and seal tubules in dentin ${ }^{2}$, reducing the level of mutans streptococci in exposed root surfaces ${ }^{38}$. Nonetheless, we found no studies assessing the efficacy of EC40 ${ }^{\mathrm{TM}}$ in root canals against $E$. faecalis.

$\mathrm{CHX}$ can be used alone or combined with surfactant agents such as cetrimide $(\mathrm{CTR})^{9}$; in turn, CTR is a cationic surfactant largely used in endodontics in conjunction with other irrigants. When combined with $\mathrm{CHX}$, it is capable of eliminating $E$. faecalis planktonic cultures ${ }^{24}$ as well as biofilms ${ }^{3}$. Considering the antimicrobial efficacy of $\mathrm{CHX}$ in root canals, the objective of the present study was to assess the influence of different final irrigation protocols, using diverse concentrations and $\mathrm{CHX}$ vehicles, in the coronal leakage of $E$. faecalis in filled root canals.

\section{MATERIAL AND METHODS}

Seventy freshly extracted mandibular incisor teeth with single, straight root canals and fully developed apices were collected. Any remaining tissue was mechanically removed using a curette, without producing damage to the root surface. The teeth were cleaned with $0.5 \% \mathrm{NaOCl}$ and then stored in $0.9 \%$ sterile normal saline solution at room temperature until use.

The crowns were removed and the coronal surfaces of the root were sectioned perpendicular to the long axis of the root using a turbine handpiece and a diamond bur. To ensure uniformity in the samples, the root length was set at approximately $15 \mathrm{~mm}$ from the coronal surface to the apex of the root. The protocol was approved by the Ethics Committee of the University of Granada.

\section{Root canal preparation}

All the teeth were prepared by the same operator. The patency of each canal was confirmed by inserting an ISO size $10 \mathrm{~K}$ file (Dentsply Maillefer, Ballaigues, Switzerland) until the tip was just visible at the apical foramen. The working length was determined by subtracting $1 \mathrm{~mm}$ from the length. The root canals were prepared using ProTaper instruments (Dentsply Maillefer) with the crown-down technique recommended by the manufacturer; all were enlarged with a F3 file (finishing file number 3; taper 0.09-0.05; size 30).
A size $10 \mathrm{~K}$ file was used between each ProTaper instrument to verify the patency of the canal.

\section{Irrigation protocols}

Next, the irrigation was carried out using a $3 \mathrm{~mL}$ Luer-Loc syringe coupled to a 30-gauge needle tip placed passively into the canal up to $2 \mathrm{~mm}$ from the apical foramen without binding. Alternating irrigation of $5 \mathrm{~mL}$ of $2.5 \% \mathrm{NaOCl}$ and $5 \mathrm{~mL}$ of $17 \%$ EDTA solutions was performed between each file. After the root canal preparation, the teeth were flushed with $10 \mathrm{~mL}$ of $2.5 \% \mathrm{NaOCl}$ and then randomly divided into four experimental groups ( $n=15$ ) according to the final irrigation protocol. Group I was without final irrigation. The other three groups, before the final irrigation regimen, were flushed with $5 \mathrm{~mL}$ distilled water and dried with F3 paper points (Dentsply Maillefer). Group II received a final flush with $10 \mathrm{~mL}$ of $2.0 \% \mathrm{CHX}$ solution; Group III a final application of $\mathrm{EC} 40^{\mathrm{TM}}$ varnish (Biodent, Nijmegen, The Netherlands) using a microbrush at an established length of $15 \mathrm{~mm}$ from the canal orifice; and Group IV, a final flush with $10 \mathrm{~mL}$ of $0.2 \% \mathrm{CHX}+0.1 \% \mathrm{CTR}$. To prepare this combination, both solutions were prepared at double concentration and mixed $1: 1$ to obtain the desired concentrations in the mixture. All the root canals were dried after the final irrigation protocols with F3 absorbent paper points.

Ten teeth served as controls: 5 positive (roots that were not obturated) and 5 negative (teeth with intact crowns).

The root canals were filled using a F3 master gutta-percha point (Dentsply Maillefer) and AH Plus ${ }^{\circledR}$ sealer (Dentsply Maillefer). Lateral condensation was performed using a \#25 spreader (Dentsply Maillefer). The gap left by the spreader was filled with \#25 gutta-percha points. The excess guttapercha was cut off using a hot instrument, and the coronal portion of the warm gutta-percha was firmly condensed vertically. All these samples were stored at $37^{\circ} \mathrm{C}$ for 72 hours to allow the sealer to set.

\section{Microbial leakage test}

The external surfaces of all teeth, except $2 \mathrm{~mm}$ around the apical foramen, were covered with two layers of nail varnish in order to prevent bacterial leakage through the lateral canals. The negative controls were fully covered by two layers of varnish.

The microbial test consisted of a 2-chamber method $^{10}$. The upper chamber contained $1.5 \mathrm{~mL}$ Eppendorf plastic tubes (Elkay, Shrewbury, MA, USA) tapered and cut to receive the root end. The interface between the tooth and the Eppendorf tube was put into the rubber cork of a penicillin bottle previously cut to fit inside the lower chamber. The junctions between the root, the Eppendorf tube and the rubber cork were sealed with cyanoacrylate 
adhesive (Super Glue-3, Henkel Ibérica, S.A., Barcelona). The mounts were sterilized for 45 minutes in hydrogen peroxide gas plasma (Sterrad-50, Advanced Sterilization Products, Johnson \& Johnson, Irvine, CA, USA).

After sterilization, the apparatus was placed in a glass flask (the lower chamber) containing sterile Brain Heart Infusion broth (BHI, Scharlau Chemie S.A., Barcelona, Spain). The root tip had 2-3 mm immersed in the broth. The junctions between the Eppendorf tubes and the glass flasks were tightly sealed with Parafilm $\mathrm{M}^{\mathrm{TM}}$ (Pechiney Plastic Packaging, Chicago, IL, USA) and cyanoacrylate adhesive.

An initial bacterial suspension containing $6 \times 10^{8}$ CFU/mL of $E$. faecalis (ATCC 29212) was obtained in a turbidimeter (bioMérieux S.A., Densichek Plus, NC, USA). The Eppendorf reservoirs were filled with $1 \mathrm{~mL}$ of the initial suspension keeping the bacterial suspension in contact with the coronal portion of the filled roots. The mounts were always handled in sterile conditions under a laminar flow hood (Nuaire, Plymouth, MN, USA) to avoid bacterial contamination. They were placed in an oven at $37^{\circ} \mathrm{C}$ during a period of 180 days. The culture

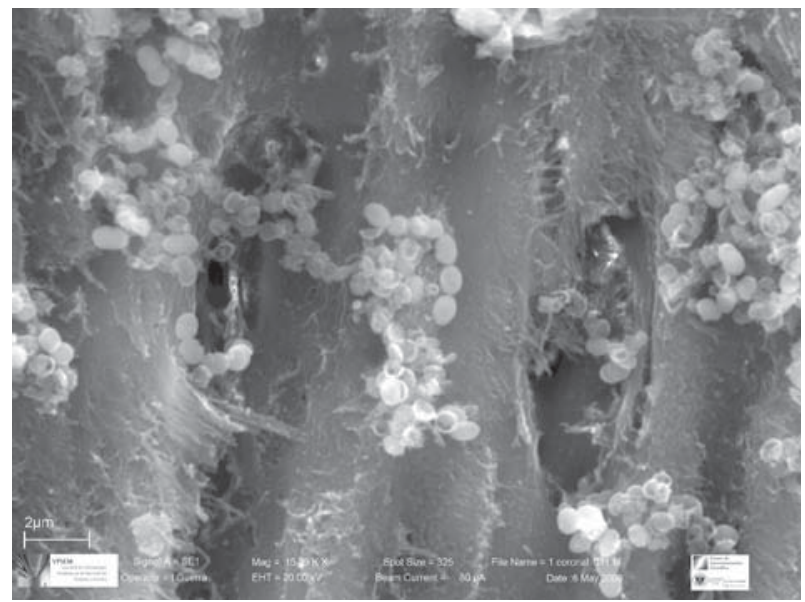

Figure 1- Scanning electron microscopy (SEM) micrograph. E. faecalis biofilm attached to the root canal wall and entering the dentinal tubule medium in the upper chamber was replaced with freshly grown broth twice a week. The viability and purity of the bacteria were checked every week by seeding some in blood agar plates and observing the colony morphology.

The lower chambers of all mounts were observed daily, the turbidity time was recorded for each specimen as an indicator of entire root canal contamination. Once turbidity was present, a sample of the turbid broth was streaked onto blood agar plates and the bacteria were identified to ensure that there was no contamination other than $E$. faecalis. The presence of $E$. faecalis in the root canal walls was confirmed under scanning electron microscopy (Figure 1).

\section{Statistical analysis}

The number and percentage of specimens not leaking were determined for each group in the five evaluation periods $(45,60,90,120$ and 180 days). Since the assessment of the days of bacterial leakage did not show a normal distribution, the Friedman test was used to evaluate the significance of the differences over time for the four irrigating protocols, as well as for the paired comparisons. Moreover, the significance and sign of the slope regression over time served to study the intragroup behaviour of the irrigating protocol. The level of statistical significance was set at $5 \%$. All statistical analyses were performed with the SPSS 15.0 software (SPSS Inc, Chicago, IL, USA).

\section{RESULTS}

Table 1 shows the percentage of specimens with no leakage at the different periods of evaluation, and the comparisons among the groups. No leakage was observed in the negative control group at any time period of study. The positive control group leaked on the second day.

The global comparison among the groups, simultaneously taking into account the five evaluation periods using the Friedman global model, gave significant differences with a value

Table 1- Specimens not leaking in the different time periods (initial sample $n=15$ in each group)

\begin{tabular}{lccccc}
\hline & \multicolumn{5}{c}{ Evaluated times (days) } \\
\multicolumn{1}{c}{ FINAL PROTOCOL } & $\mathbf{n}(\%)$ & $\mathbf{6 0}$ & $\mathbf{9 0}$ & $\mathbf{1 2 0}$ & $\mathbf{1 8 0}$ \\
\hline $2.5 \% \mathrm{NaOCl}^{*}$ & $13(86.7)$ & $12(80.0)$ & $11(73.3)$ & $9(40.0)$ & $3(20.0)$ \\
$2 \% \mathrm{CHX}^{*},{ }^{* *}$ & $15(100.0)$ & $15(100.0)$ & $10(66.7)$ & $7(46.7)$ & $3(20.0)$ \\
\hline $\mathrm{EC}^{\mathrm{TM}}$ varnish $^{* *}$ & $15(100.0)$ & $15(100.0)$ & $14(93.3)$ & $9(60.0)$ & $5(33.3)$ \\
$0.2 \% \mathrm{CHX}+0.1 \% \mathrm{CTR}^{*}$ & $12(80.0)$ & $12(80.0)$ & $9(60.0)$ & $8(53.3)$ & $1(6.7)$ \\
\hline
\end{tabular}

The same superscript small asterisks show statistically similar groups according to the Friedman test. In all cases $p<0.05$ is considered a statistically significant difference. 
of $p=0.021$. The results of the pair-by-pair comparisons between protocols accounting for the five evaluation periods can be viewed in the Table. EC40 ${ }^{\mathrm{TM}}$ exhibited a similar behaviour to $2 \% \mathrm{CHX}$. Yet, in the 90 day period, the $\mathrm{EC} 40^{\mathrm{TM}}$ group had only one leaked sample, in contrast with the five samples showing leakage in the $2 \% \mathrm{CHX}$ group. $\mathrm{EC} 40^{\mathrm{TM}}$ had significant differences when compared to the $2.5 \%$ $\mathrm{NaOCl}$ group and the group $0.2 \% \mathrm{CHX}+0.1 \% \mathrm{CTR}$. No significant differences were observed between the $2.5 \% \mathrm{NaOCl}$ group and the $2 \% \mathrm{CHX}$ group or $0.2 \% \mathrm{CHX}+0.1 \% \mathrm{CTR}$.

The slopes of the regression models relating to the percentage of non-leaked specimens with the time period were statistically significant and negative for all the irrigating protocols, thereby showing an intra-group reduction of non-leaking over time.

\section{DISCUSSION}

Obtaining hermetic tri-dimensional sealing of a root canal is essential for isolating the microorganisms that may remain after biomechanical preparation and preventing their entry from the oral cavity ${ }^{30,32}$. In this sense, coronal restoration is an important requisite for long-term endodontic success, and restorative materials should provide a permanent, leak-proof seal. Defective temporary or permanent restoration, during or after root canal treatment, is known to be a main cause of coronal leakage ${ }^{8}$.

Several studies have shown that coronal micro-leakage can occur with any of the different obturation techniques used ${ }^{10,26}$. However, the irrigation procedure seems to play a key role in the success of endodontic treatment, as it can delay or decrease bacterial contamination of the treated canal $^{21,35}$. Therefore, in order to enhance efficient antimicrobial action over time, the use of irrigating solutions with a residual antiseptic capacity, such as $\mathrm{CHX}$, is recommended ${ }^{22}$, although it is not effective for smear layer or debris removal ${ }^{33}$.

Diverse in vitro methods for evaluating the sealing ability of root canal filling materials have involved the use of dyes, scanning electron microscopy, fluid filtration techniques, electrochemical methods, radioisotopes, and bacteria ${ }^{34}$. Evaluation of coronal leakage by bacteria provides data that are more biologically significant and clinically relevant than other methods ${ }^{34}$. In our study, the 2-chamber model described by Imura, et al. ${ }^{19}$ (1997) and modified by De-Deus, et al. ${ }^{10}$ (2005) was applied. It is a static model that does not exactly simulate clinical conditions, requiring a long period of observation, and not allowing for quantification of the number of penetrating bacteria ${ }^{30}$. In addition, the presence of leakage evaluated as positive turbidity is a binary variable that is not very accurate. The bacteria selected for our study was E. faecalis, often isolated from necrotic or improperly filled root canal systems, as well as from properly filled ones ${ }^{16}$. E. faecalis ATCC 29212 is a strain of reference widely used in antimicrobial susceptibility studies, and it exhibits a great capacity for forming biofilms ${ }^{20}$.

Mandibular incisors with single oval canals were used in this study. It is known that the prevalence of long oval root canals in the apical third of mandibular incisors is $\geq 50 \%{ }^{39}$, representing a great challenge for proper cleaning and disinfection of the root canal ${ }^{1,27}$. In canals with these anatomical conditions, hand and rotary instruments work in reaming motion and would leave some uninstrumented recesses, which have the potential to harbour persistent bacteria ${ }^{7,36}$. In this sense, instruments with greater taper, like the ProTaper, are more efficient than $\mathrm{NiTi}$ - hand files, but in some cases, at the expense of remaining dentinwall thickness ${ }^{13}$. Moreover, the quality of the root fillings in oval canal-mandibular incisors may be compromised ${ }^{31}$; however, different obturation techniques in oval-shaped canals have not shown statistical differences ${ }^{10,11}$.

Preparation of root canals was similar in all the groups of our study and included sequential use of $2.5 \% \mathrm{NaOCl}$ and $17 \%$ EDTA with a final flush of $2.5 \% \mathrm{NaOCl}$. However, all groups were not treated with the same amount of final irrigating solution, which may have influenced the results. The regimen of final irrigation has been shown to influence the capacity of adherence of $E$. faecalis ${ }^{21}$. Alternating use of $\mathrm{NaOCl}$ and EDTA can prove to be beneficial. $\mathrm{NaOCl}$ can dissolve organic matter and necrotic tissue as well as exert strong antimicrobial action ${ }^{14}$. In turn, EDTA is able to remove the smear layer $^{40}$ formed during preparation of the root canal, although its antimicrobial activity is still a matter of debate. Using $\mathrm{NaOCl}$ as the final irrigating solution is widely recommended ${ }^{40}$, but it has not demonstrated any residual antibacterial activity ${ }^{23}$.

A $2 \% \mathrm{CHX}$ solution is recommended as the final irrigant in the root canal preparation ${ }^{22}$. Nevertheless, the use of a $\mathrm{CHX}$ varnish such as $\mathrm{EC} 40^{\mathrm{TM}}$ has not been tested in endodontics. Our results indicate that the delay of leakage was greater in the $\mathrm{EC} 40^{\mathrm{TM}}$ group, while the $2 \% \mathrm{CHX}$ group showed an intermediate effectiveness. Vivacqua-Gomes, et al. ${ }^{35}$ (2002) obtained better results with a $2 \% \mathrm{CHX}$ gel than with a $2 \% \mathrm{CHX}$ solution, suggesting the importance of the vehicle of application. Moreover, the antimicrobial substantivity of $\mathrm{CHX}$ depends on the number of $\mathrm{CHX}$ molecules available to interact with the dentin ${ }^{22}$, and EC40 ${ }^{\mathrm{TM}}$ has a very high concentration of this active agent. White, et al. ${ }^{37}$ (1997) evaluated substantial antimicrobial activity in instrumented root canals using $2.0 \%$ and $0.12 \%$ 
$\mathrm{CHX}$ as irrigants; their results indicated that the antimicrobial activity remaining in the $2 \% \mathrm{CHX}$ treated teeth was significantly greater than in the $0.12 \% \mathrm{CHX}$-treated teeth.

Another factor to bear in mind is the vehicle used. $\mathrm{EC} 40^{\mathrm{TM}}$ can be considered a slow release device, and varnishes were formulated with the objective of prolonging the delivery of the active agent. Attin, et al. ${ }^{5}$ (2008) observed a greater release of $\mathrm{CHX}$ on bovine dentin fissures treated with $\mathrm{CHX}$ varnishes as compared to dentin treated with $\mathrm{CHX}$ preparations, in gel or in solution. Their study found the varnish providing the best release of $\mathrm{CHX}$ to be $\mathrm{EC} 40^{\mathrm{TM}}$. Attin, et al. ${ }^{4}$ (2003) and Derks, et al. ${ }^{12}$ (2008) compared the efficacy of different concentrations of $\mathrm{CHX}$ in varnish (EC40 ${ }^{\mathrm{TM}}$, Cervitec) in reducing the levels of mutans streptococci, lactobacilli and in plaque formation in interproximal plaque and saliva. According to their findings, application of the highly concentrated varnish $\mathrm{EC}^{\mathrm{TM}}$ results in a higher decrease of mutans streptococci in plaque sites and saliva. Furthermore, it should be emphasized that the $2 \% \mathrm{CHX}$ was a solution, and since the root canals were dried with paper points, it would have been better removed than the varnish.

Although it was recently demonstrated that the association of $\mathrm{CHX}$ and CTR enhances the in vitro capacity to eradicate $E$. faecalis biofilm ${ }^{3}$, our results for the group $0.2 \% \mathrm{CHX}+0.1 \%$ CTR showed no differences with respect to the control group. This may be due to the relatively low concentration of $\mathrm{CHX}$, promoting a less intense substantive action.

Notwithstanding, high concentrations of $\mathrm{CHX}$ in the form of a varnish (EC40 ${ }^{\mathrm{TM}}$ ) would appear to ensure some delay in coronal leakage. Further investigations are needed to evaluate the efficacy of different vehicles and concentrations of $\mathrm{CHX}$ and to assess how they might affect the complete sealing of the root canal.

\section{CONCLUSION}

In this ex vivo study, high concentrations of $\mathrm{CHX}$ in the form of a varnish (EC40 ${ }^{\mathrm{TM}}$ ) would appear to ensure some delay in coronal leakage.

\section{REFERENCES}

1- Alves FR, Almeida BM, Neves MA, Moreno JO, Rôças IN, Siqueira JF Jr. Disinfecting oval-shaped root canals: effectiveness of different supplementary approaches. J Endod. 2011;37:496-501. 2- Arends J, Duschner H, Ruben JL. Penetration of varnishes into demineralized root dentine in vitro. Caries Res. 1997;31:201-5. 3- Arias-Moliz MT, Ferrer-Luque CM, González-Rodríguez MP, Valderrama MJ, Baca P. Eradication of Enterococcus faecalis biofilms by cetrimide and chlorhexidine. J Endod. 2010;36:87-90. 4- Attin R, Tuna A, Attin T, Brunner E, Noack MJ. Efficacy of differently concentrated chlorhexidine varnishes in decreasing Mutans streptococci and lactobacilli counts. Arch Oral Biol. 2003;48:503-9.
5- Attin T, Abouassi T, Becker K, Viegand A, Roos M, Attin R. A new method for chlorhexidine ( $\mathrm{CHX}$ ) determination: $\mathrm{CHX}$ release after application of differently concentrated $\mathrm{CHX}$-containing preparations on artificial fissures. Clin Oral Investig. 2008;12:189-96.

6- Ballal V, Kundabala M, Acharya S, Ballal M. Antimicrobial action of calcium hydroxide, chlorhexidine and their combination on endodontic pathogens. Aust Dent J. 2007;52:118-21.

7- Barbizam JV, Fariniuk LF, Marchesan MA, Pecora JD, Sousa-Neto $M D$. Effectiveness of manual and rotary instrumentation techniques for cleaning flattened root canals. J Endod. 2002;28:365-6.

8- Chong BS. Coronal leakage and treatment failure. J Endod. $1995 ; 21: 159-60$.

9- D'Arcangelo C, Varvara G, De Fazio P. An evaluation of the action of different root canal irrigants on facultative aerobicanaerobic, obligate anaerobic, and microaerophilic bacteria. J Endod. 1999;25:351-3.

10- De Deus G, Murad C, Paciornik S, Reis CM, Coutinho-Filho T. The effect of the canal-filled area on the bacterial leakage of oval-shaped canals. Int Endod J. 2008;41:183-90.

11- De Deus G, Murad CF, Reis CM, Gurgel-Filho E, Coutinho Filho T. Analysis of the sealing ability of different obturation techniques in oval-shaped canals: a study using a bacterial leakage model. Braz Oral Res. 2006;20:64-9.

12- Derks A, Frencken J, Bronkhorst E, Kuijpers-Jagtman AM, Katsaros C. Effect of chlorhexidine varnish application on mutans streptococci counts in orthodontic patients. Am J Orthod Dentofacial Orthop. 2008;133:435-9.

13- Elayouti A, Chu AL, Kimionis I, Klein C, Weiger R, Löst C. Efficacy of rotary instruments with greater taper in preparing oval root canals. Int Endod J. 2008;41:1088-92.

14- Estrela C, Silva JA, Alencar AH, Leles CR, Decurcio DA. Efficacy of sodium hypochlorite and chlorhexidine against Enterococcus faecalis-a systematic review. J Appl Oral Sci. 2008;16:364-8. 15- Ferraz CC, Gomes BP, Zaia AA, Teixeira FB, Souza-Filho FJ. Comparative study of the antimicrobial efficacy of chlorhexidine gel, chlorhexidine solution and sodium hypochlorite as endodontic irrigants. Braz Dent J. 2007;18:294-8.

16- Figdor D, Sundqvist G. A big role for the very smallunderstanding the endodontic microbial flora. Aust Dent J. 2007;52:S38-51.

17- Gerardu VA, Buijs MJ, ten Cate JM, Loveren C. Effect of an intensified treatment with $40 \%$ chlorhexidine varnish on plaque acidogenicity. Clin Oral Investig. 2007;11:77-81.

18- Gomes BP, Sato E, Ferraz CC, Teixeira FB, Zaia AA, Souza-Filho FJ. Evaluation of time required for recontamination of coronally sealed canals medicated with calcium hydroxide and chorhexidine. Int Endod J. 2003;36:604-9.

19- Imura N, Otani SM, Campos MJA, Jardim EG Jr, Zuolo ML. Bacterial penetration through temporary restorative materials in root canal treated teeth in vitro. Int Endod J. 1997;30:381-5. 20- Jefferson KK. What drives bacteria to produce biofilm? FEMS Microbiol Lett. 2004;236:163-73.

21- Kishen A, Sum CP, Mathew S, Lim CT. Influence of irrigation regimens on the adherence of Enterococcus faecalis to root canal dentin. J Endod. 2008;34:850-4.

22- Mohammadi Z, Abbott PV. The properties and applications of chlorhexidine in endodontics. Int Endod J. 2009;42:288-302. 23- Mohammadi Z, Shahriari S. Residual antibacterial activity of chlorhexidine and MTAD in human root dentin in vitro. J Oral Sci. 2008;50:63-7.

24- Onçağ O, Hoşgör M, Hilmioğlu S, Zekioğlu O, Eronat C, Burhanoğlu D. Comparison of antibacterial and toxic effects of various root canal irrigants. Int Endod J. 2003;36:423-32.

25- Pérez-Heredia M, Ferrer-Luque CM, González-Rodríguez MP. The effectiveness of different acid irrigating solutions in root canal cleaning after hand and rotary instrumentation. J Endod. 2006;32:993-7.

26- Saleh IM, Ruyter IE, Haapasalo M, Ørstavik D. Bacterial penetration along different root canal filling materials in the presence or absence of smear layer. Int Endod J. 2008;41:32-40. 
27- Siqueira JF Jr, Alves FR, Almeida BM, Oliveira JC, Rôças IN. Ability of chemo-mechanical preparation with either rotary instruments or self-adjusting file to disinfect oval-shaped root canals. J Endod. 2010;36:1860-5.

28- Siqueira JF Jr, Rôças IN, Lopes HP, Uzeda M. Coronal leakage of two root canal sealers containing calcium hydroxide after exposure to human saliva. J Endod. 1999;25:14-6.

29- Souza-Filho FJ, Soares AJ, Vianna ME, Zaia AA, Ferraz CC, Gomes BP. Antimicrobial effect and $\mathrm{pH}$ of chlorhexidine gel and calcium hydroxide alone and associated with other materials. Braz Dent J. 2008;19:28-33.

30- Swanson K, Madison S. An evaluation of coronal micro-leakage in endodontically treated teeth. Part I. Time periods. J Endod. 1987;13:56-9.

31- Van der Sluis LW, Wu MK, Wesselink PR. An evaluation of the quality of root fillings in mandibular incisors and maxillary and mandibular canines using different methodologies. J Dent. 2005;33:683-8.

32- Vasconcelos BC, Bernardes RA, Duarte MA, Bramante CM, Moraes IG. Apical sealing of root canal fillings performed with five different endodontic sealers: analysis by fluid filtration. J Appl Oral Sci. 2011;19:324-8.
33- Vasconcelos BC, Luna-Cruz SM, De-Deus G, Moraes IG, Maniglia-Ferreira C, Gurgel-Filho ED. Cleaning ability of chlorhexidine gel and sodium hypochlorite associated or not with EDTA as root canal irrigants: a scanning electron microscopy study. J Appl Oral Sci. 2007;15:387-91.

34- Veríssimo DM, Vale MS. Methodologies for assessment of apical and coronal leakage of endodontic filling materials: a critical review. J Oral Sci. 2006;48:93-8.

35- Vivacqua-Gomes N, Ferraz CC, Gomes BP, Zaia AA, Teixeira $F B$, Souza-Filho FJ. Influence of irrigants on the coronal microleakage of laterally condensed gutta-percha root fillings. Int Endod J. 2002;35:791-5.

36- Weiger R, Elayouti A, Löst C. Efficiency of hand and rotary instruments in shaping oval root canals. J Endod. 2002;28:580-3. 37- White RR, Hays GL, Janer LR. Residual antimicrobial activity after canal irrigation with chlorhexidine. J Endod. 1997;23:229-31. 38- Wicht MJ, Haak R, Lummert D, Noack MJ. Treatment of root caries lesions with chlorhexidine-containing varnishes and dentin sealants. Am J Dent. 2003;16(Spec No):25A-30A.

39- Wu MK, R'oris A, Barkis D, Wesselink PR. Prevalence and extent of long oval canals in the apical third. Oral Surg Oral Med Oral Pathol Oral Radiol Endod. 2000;89:739-43.

40- Zehnder M. Root canal irrigants. J Endod. 2006;32:389-98. 